cambridge.org/zyg

\section{Review Article}

Cite this article: Itoi F et al. (2022) Importance of real-time measurement of sperm head morphology in intracytoplasmic sperm injection. Zygote. 30: 9-16. doi: 10.1017/ S0967199421000307

Received: 10 March 2021

Revised: 5 April 2021

Accepted: 14 April 2021

First published online: 14 May 2021

\section{Keywords:}

Assisted reproductive technology; Intracytoplasmic sperm injection; Real-time sperm selection system; Sperm head size; Sperm selection

\section{Authors for correspondence:}

Fumiaki Itoi, Department of Reproduction Center, Komaki City Hospital, Jobushi 1-20, Komaki, Aichi 485-8520, Japan;

Tel: +81-568-76-4131.

E-mail: itofumi1980@gmail.com

Jun Ueda, Department of Advanced Medical Science, Asahikawa Medical University, Asahikawa, Hokkaido 078-8510, Japan; Tel: +81-166-68-2385.

E-mail: junueda@asahikawa-med.ac.jp

†Present affiliation: Department of Obstetrics and Gynecology, Dokkyo Medical University, Tochigi 321-0293, Japan (c) The Author(s), 2021. Published by Cambridge University Press. This is an Open Access article, distributed under the terms of the Creative Commons Attribution licence (http:// creativecommons.org/licenses/by/4.0), which permits unrestricted re- use, distribution and reproduction, provided the original article is properly cited.

\section{CAMBRIDGE} UNIVERSITY PRESS

\title{
Importance of real-time measurement of sperm head morphology in intracytoplasmic sperm injection
}

Fumiaki Itoi ${ }^{1}$ (1), Toshinobu Miyamoto ${ }^{2} \dagger$, Takehiro Himaki $^{3}$, Hiroyuki Honnma ${ }^{4}$, Miho Sano ${ }^{1}$ and Jun Ueda ${ }^{5}$

${ }^{1}$ Department of Reproduction Center, Komaki City Hospital, Komaki, Aichi 485-8520, Japan; ${ }^{2}$ Japanese Red Cross Society, Asahikawa Blood Center, Hokkaido 070-8530, Japan; ${ }^{3}$ Faculty of Applied Biological Sciences, Gifu University, Gifu 501-1193, Japan; ${ }^{4}$ Sapporo ART Clinic, Hokkaido 060-0807, Japan and ${ }^{5}$ Department of Advanced Medical Science, Asahikawa Medical University, Hokkaido 078-8510, Japan

\begin{abstract}
Summary
Intracytoplasmic sperm injection (ICSI) is an important technique in male infertility treatment. Currently, sperm selection for ICSI in human assisted reproductive technology (ART) is subjective, based on a visual assessment by the operator. Therefore, it is desirable to develop methods that can objectively provide an accurate assessment of the shape and size of sperm heads that use low-magnification microscopy available in most standard fertility clinics. Recent studies have shown a correlation between sperm head size and shape and chromosomal abnormalities, and fertilization rate, and various attempts have been made to establish automated computer-based measurement of the sperm head itself. For example, a dictionary-learning technique and a deep-learning-based method have both been developed. Recently, an automatic algorithm was reported that detects sperm head malformations in real time for selection of the best sperm for ICSI. These data suggest that a real-time sperm selection system for use in ICSI is necessary. Moreover, these systems should incorporate inverted microscopes ( $\times 400-600$ magnification) but not the fluorescence microscopy techniques often used for a dictionary-learning technique and a deep-learning-based method. These advances are expected to improve future success rates of ARTs. In this review, we summarize recent reports on the assessment of sperm head shape, size, and acrosome status in relation to fertility, and propose further improvements that can be made to the ARTs used in infertility treatments.
\end{abstract}

\section{The current situation in fertility clinics worldwide}

Forty-two years have passed since Drs. Robert Edwards and Patrick Steptoe in the UK reported the first successful birth of a child following in vitro fertilization (IVF) (Steptoe and Edwards, 1978). Furthermore, 28 years have passed since the birth of the first child conceived using intracytoplasmic sperm injection (ICSI) technology (Palermo et al., 1992). Importantly, Louise Brown, the first baby born as a result of IVF, subsequently gave birth herself to a healthy child following an unassisted conception and an uneventful pregnancy. This event showed that IVF had no adverse effect on the reproductive capacity of offspring born using assisted reproductive technology (ART).

Recent advances in ART have allowed many infertile couples to have children. However, due to societal changes such as delays both in marriage and in starting a family, the number of patients attending fertility clinics is increasing and the number of births to older parents worldwide is also increasing. Globally, the number of patients treated using ART is increasing every year (Calhaz-Jorge et al., 2017; Irahara et al., 2017; De Geyter et al., 2018; Sunderam et al., 2020). In Europe, the number of ICSI cases is more than double the number of IVF treatments (Calhaz-Jorge et al., 2017; De Geyter et al., 2018). Even in Japan, the number of ICSI cases is also increasing annually (Irahara et al., 2017).

The fact that up to half the cases of infertility in humans are due to male infertility (Irvine, 1998 ) is less commonly recognized. Most investigations into the causes of infertility have been carried out on females and, until recently, comparatively little attention has been paid to males. Concomitant with the increase in maternal age of pregnancy, paternal age has also risen. This rise has led to the recent investigation of the relationships between paternal age and the quality of spermatozoa, embryogenesis, and clinical outcomes (Belloc et al., 2009; Alshahrani et al., 2014; Sagi-Dain et al., 2015; Sharma et al., 2015; Wu et al., 2016; Chapuis et al., 2017; Bartolacci et al., 2018; Kaarouch et al., 2018). These studies have shown that sperm parameters diminish with paternal ageing. Moreover, embryo quality and blastocyst formation rates also worsen with paternal ageing (Frattarelli et al., 2008; Luna et al., 2009; Wu et al., 2016), although clinical and neonatal outcomes do not appear to be affected (Frattarelli et al., 2008; Luna et al., 
2009; Sagi-Dain et al., 2015; Wu et al., 2016). Conversely, it has also been reported that both severe male factor infertility and the use of ICSI itself slightly increase the risk of mental retardation and autism in offspring (Sandin et al., 2013; Kissin et al., 2015; Rumbold et al., 2019). Nevertheless, it is important to obtain good quality embryos and blastocysts for use in ART. To this end, ICSI is generally performed following sperm selection according to World Health Organization (WHO) criteria (Table 1) (World Health Organization, 2010). Established sperm selection methods are subjective and based on morphological features such as the shape and size of the sperm head, midpiece, and tail and by the presence or absence of vacuoles within the sperm head, and size of acrosome (Figure 1). However, as sperm selection based on sperm head size is subjective and made by the embryologists who perform the ICSI protocol, it is possible that this subjective selection process may affect the clinical outcome. Therefore, we felt it would be timely to review the current understanding of the relationship between sperm head morphology and fertilization from the standpoint of human ART and ICSI. In this review, we also consider the relationship between sperm head size and chromatin proteins. Finally, we summarize studies on sperm head shape and fertility and propose potential improvements for ART in infertility treatment.

\section{The relationship between sperm shape and chromatin proteins}

Sperm cells are produced in the seminiferous tubules of the testes. During spermatogenesis, spermatogonial stem cells give rise to differentiating spermatogonia that undergo dramatic morphological change to eventually become fertilization-competent mature spermatozoa (Clermont, 1972; Griswold, 2016).

Spermatogenesis has two major steps, spermatocytogenesis and spermiogenesis (Griswold, 2016). Spermatocytogenesis is the process of cell division from mitosis of spermatogonia to the production of haploid round spermatids by meiosis of spermatocytes. Conversely, spermiogenesis is the process by which round spermatids transform into sperm via elongated spermatids. During spermiogenesis, the nuclei of the spermatids become condensed and a midpiece is developed along with a tail for motility. At the end of this differentiation process, the cells have formed streamlined spermatozoa. The gametes undergo further modifications during their movement from the caput to the cauda epididymis (Bedford and Calvin, 1974), to produce functional sperm capable of fertilization.

Mashiko et al. (2017) monitored the changes in the heads of mouse spermatozoa as the cells transited from the caput to the cauda epididymis, and in the uterus post coitus until they reached the perivitelline space of oocytes in the oviduct, just before fertilization (Mashiko et al., 2017). They found that during the maturation of spermatozoa (following transit from the caput epididymis to the corpus and then to the cauda), sperm heads became thinner and the ratio of length to width (the so-called aspect ratio) of the sperm head became larger. Notably, after ejaculated sperm entered the uterus and swam through the oviduct to the oocytes, there were no significant changes in the aspect ratio. Intriguingly, the authors found that the spermatozoa that penetrated the zona pellucida had statistically thinner heads than those in the cauda epididymis. It is not known why spermatozoa with thinner heads appear to have a higher survival, but it may be that the thinner head is advantageous for passing between cumulus cells to reach the egg. As noted below, embryologists at clinics empirically choose spermatozoa with thinner heads for ICSI.
Eukaryotic genomic DNA is wrapped around basic proteins called histones and is tightly folded for compact storage within the cell nucleus. During spermatogenesis, many chromatin-related proteins are produced that remodel chromatin structure in spermatogonia and spermatocytes, enabling meiotic recombination in the latter cell type (Govin et al., 2004; Zhao et al., 2004; Ueda et al., 2017). Moreover, in a process called histone-to-protamine transition, histones are replaced with strong basic proteins named protamines (Govin et al., 2004). This change alters the circular or ellipsoid shape of the nucleus to become the characteristic shape of spermatozoa (the actual sperm head shape varies among species). Interestingly, not all histones are replaced by protamines, and the amount of histone replaced varies among species. For example, in mice, $92-99 \%$ of histones in the cell nucleus are replaced by protamines (Brykczynska et al., 2010; Jung et al., 2017; Yamaguchi et al., 2018), while in humans, approximately $10-15 \%$ of histones remain in mature spermatozoa (Hammoud et al., 2009). It is presumed that the remaining histones, together with other chromatin-related proteins, affect the morphology and size of the sperm head. Male mammals produce very large numbers of spermatozoa during their lifetimes. We speculate that the relative amounts of histones and chromatin-related proteins in each sperm head may be highly heterogeneous and therefore cause the variability observed in shape and size of each sperm head. Application of recently developed single-cell technologies may provide insight into the validity of this speculation (Shapiro et al., 2013; Potter, 2018).

\section{The relationship between sperm head morphology and fertilization rate in humans}

For human ARTs, the morphology, size, and acrosome of sperm heads are important criteria for sperm selection. Kruger et al. (1988) published strict criteria for morphological evaluation of human sperm (Figure 1 and Table 1). Under these criteria, good sperm have an elliptical or barrel-shaped head, a straight midpiece that is neither swollen nor thickened, a straight tail, and an acrosome occupying c. 40-70\% of the sperm head (Kruger et al., 1988). Furthermore, normal sperm have a head length of $c .4 .1 \mu \mathrm{m}$ (range 3.7-4.7 $\mu \mathrm{m}$ ), width of $2.8 \mu \mathrm{m}$ (range $2.5-3.2 \mu \mathrm{m}$ ), and an aspect ratio of 1.5 (range 1.3-1.8) according to WHO guidelines (World Health Organization, 2010). Since the birth of the first ICSI baby in the world, described by Palermo et al. (1992), many reports on sperm morphology have been published. Currently, most embryologists who perform ICSI subjectively select sperm with a good-looking head shape and good motility among many other motile sperm. Sperm that fulfil the above criteria are selected for ICSI using an inverted microscope at $\times 200-400$ magnification (Mansour et al., 1995; Nagy et al., 1995; Svalander et al., 1996). Although it is possible to assess sperm morphology to identify obvious abnormalities of the head, midpiece, tail, and presence or absence of vacuoles within the head, it is extremely difficult to accurately determine sperm head size visually. Some studies have reported that strict sperm morphology selection for ICSI is not related to clinical outcomes such as the rates of fertilization, pregnancy, and abortion (Mansour et al., 1995; Nagy et al., 1995; Svalander et al., 1996). In contrast, De Vos et al., who classified sperm into normal and abnormal groups based on Kruger's strict criteria (Figure 1), found that the normal sperm group had significantly higher fertilization and pregnancy rates than the abnormal sperm group (De Vos et al., 2003). In addition, Cassuto et al. (2009) reported that the rate of fertilization and 
Table 1. Sperm selection methods for ICSI in human ART to date

\begin{tabular}{|c|c|c|c|c|c|}
\hline Selection methods & Method features & Advantages & Disadvantages & Clinical outcomes & References \\
\hline $\begin{array}{l}\text { Normal morphological } \\
\text { selection for ICSI }\end{array}$ & $\begin{array}{l}\text { Subjective observation of morphology and size of } \\
\text { sperm head, midpiece, and tail, and the presence } \\
\text { or absence of vacuoles within the sperm head at } \\
\text { normal magnification ( } \times 200-400) \text {. } \\
\text { WHO criteria } \\
\text { Kruger's strict criteria }\end{array}$ & $\begin{array}{l}\text { Usual method } \\
\text { Easy and fast to handle. } \\
\text { Real-time selection for ICSI }\end{array}$ & $\begin{array}{l}\text { Subjective according to } \\
\text { selection of ICSI operator }\end{array}$ & Large number & $\begin{array}{l}\text { WHO guideline (18) } \\
(32-38)\end{array}$ \\
\hline $\begin{array}{l}\text { MSOME (motile sperm } \\
\text { organelle morphology } \\
\text { examination) for IMSI }\end{array}$ & $\begin{array}{l}\text { Observation of morphology and size of head, } \\
\text { midpiece and tail, and the presence or absence } \\
\text { of vacuoles within the sperm head at high } \\
\text { magnification (more than } \times 6000 \text { ) }\end{array}$ & $\begin{array}{l}\text { Detailed observation of } \\
\text { sperm morphology and } \\
\text { vacuoles within the head. } \\
\text { Relationship between sperm } \\
\text { with abnormal } \\
\text { morphological } \\
\text { characteristics and DNA } \\
\text { fragmentation. } \\
\text { Beneficial effects on } \\
\text { indications of } \\
\text { teratozoospermia, or for } \\
\text { recurrent implantation } \\
\text { failure following ICSI. } \\
\text { Real-time selection for ICSI }\end{array}$ & $\begin{array}{l}\text { Subjective according to } \\
\text { selection of ICSI operator. } \\
\text { Takes time and is difficult to } \\
\text { handle. } \\
\text { Requires high-magnification } \\
\text { microscope (high introduction } \\
\text { cost) }\end{array}$ & Large number & $(40-50)$ \\
\hline \multirow[t]{2}{*}{$\begin{array}{l}\text { Automatic classification } \\
\text { systems }\end{array}$} & $\begin{array}{l}\text { Using dictionary-learning technique or } \\
\text { deep-learning-based method based on various } \\
\text { existing datasets at ultrahigh magnification } \\
\text { ( } \times 6300-10,000) \text { using fluorescence microscopy. } \\
\text { CE-SVM method } \\
\text { APDL method } \\
\text { VGG16 method } \\
\text { MC-HSH method }\end{array}$ & $\begin{array}{l}\text { Objective selection. } \\
\text { Detailed observation of } \\
\text { sperm morphology. } \\
\text { Can use existing datasets }\end{array}$ & $\begin{array}{l}\text { Many of the captures were } \\
\text { taken at ultrahigh } \\
\text { magnification. } \\
\text { Nongeneric technology. } \\
\text { Requires analysis software and } \\
\text { equipment }\end{array}$ & Small number & $(51-57)$ \\
\hline & $\begin{array}{l}\text { Using deep-learning-based method based on } \\
\text { nonstained and low-resolution images }\end{array}$ & $\begin{array}{l}\text { Objective selection } \\
\text { Possibility to use with } \\
\text { performing ICSI in real } \\
\text { time }\end{array}$ & $\begin{array}{l}\text { Nongeneric technology } \\
\text { Requires analysis software } \\
\text { and equipment }\end{array}$ & Small number & $(58-61)$ \\
\hline
\end{tabular}

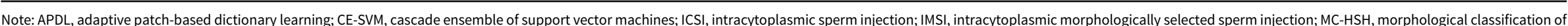
Note: APDL, adaptive patch-based dictionary learning; CE-SVM, cascade ensemble of support vector machines;
human sperm heads; VGG16, the convolutional neural network model; WHO, World Health Organization. 


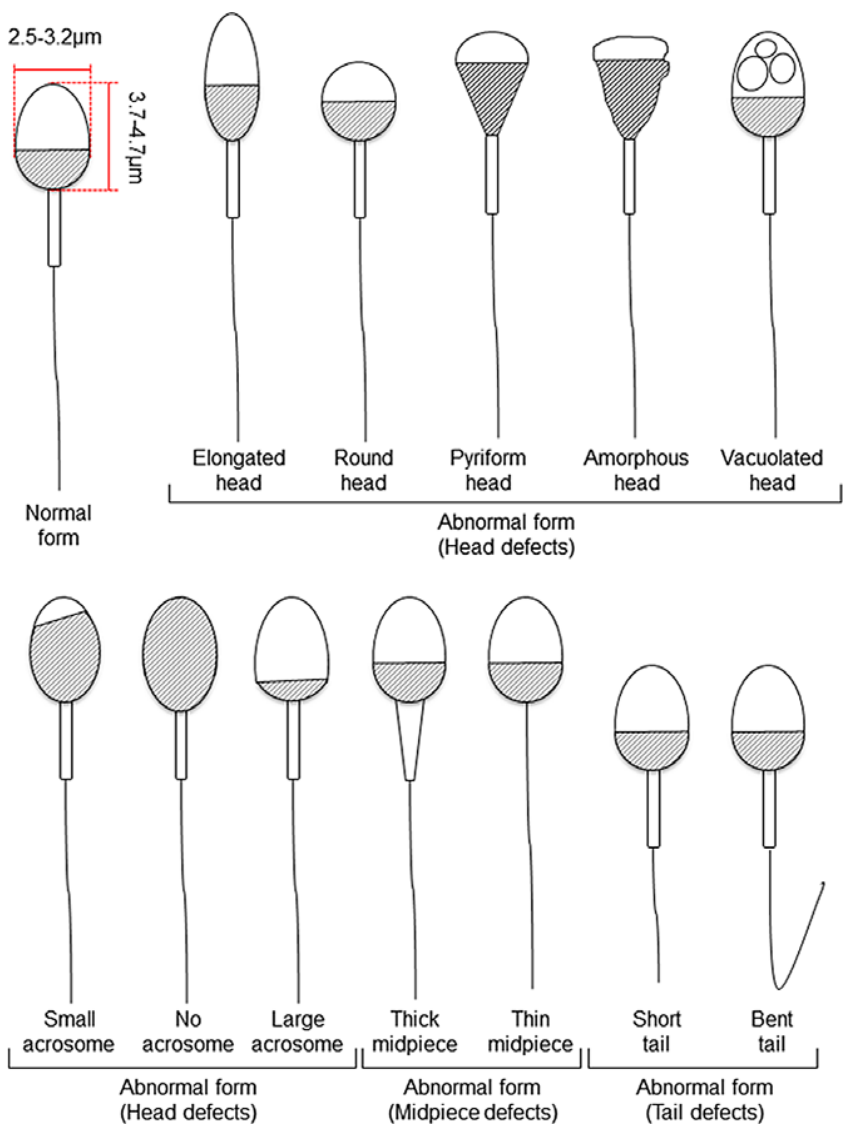

Figure 1. Schematic diagram of human sperm showing normal and abnormal forms based on Kruger's strict criteria (Kruger et al., 1988) and WHO criteria (World Health Organization, 2010).

embryo development varies among groups of sperm classified by head size and shape. Sperm heads of 3-5 $\mu \mathrm{m}$ length and width of $2-3 \mu \mathrm{m}$ gave the best results and were set as the standard. More recently, we injected human sperm into enucleated mouse oocytes, and found that a lower aspect ratio results in a decreased male pronuclear formation rate (Figure 2; Nishikawa et al., 2018). The width of the sperm head was found to be more important than its length. These findings indicate that sperm head size could affect the fertilization rate (Nishikawa et al., 2018). In contrast, Zahiri and Ghasemian reported that acrosome size and morphology of the sperm head affected sperm chromatin status as well as fertilization rates and clinical outcomes (Zahiri and Ghasemian, 2019). Sperm with small or large acrosomes significantly decreased the fertilization rates compared with those with normal acrosomes. Moreover, sperm heads with large acrosomes decreased the rates of implantation, clinical pregnancy, and live birth. It was further reported that patients with globozoospermia and patients with a predominance of abnormal acrosomes had significantly higher DNA fragmentation, and sex chromosome aneuploidy and disomy, compared with controls (Brahem et al., 2011). So far, we have described the relationship between sperm head size, shape, acrosome status, fertilization rate, and clinical outcomes. It is also important to ensure that selected sperm have no chromosomal abnormalities. However, most chromosomal tests on sperm are not performed on single spermatozoa without using bright-field images. In general, chromosomal abnormalities are detected using many sperm in combination with various staining techniques, making it impossible to use these sperm for ICSI. Overall, there
(A)

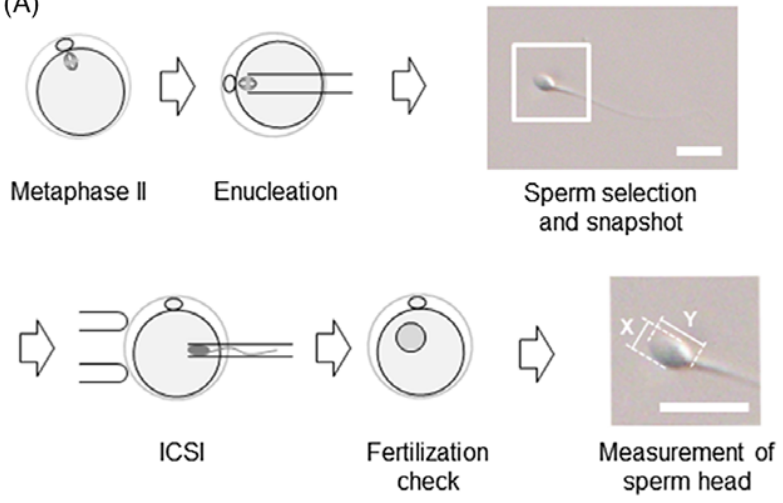

(B)

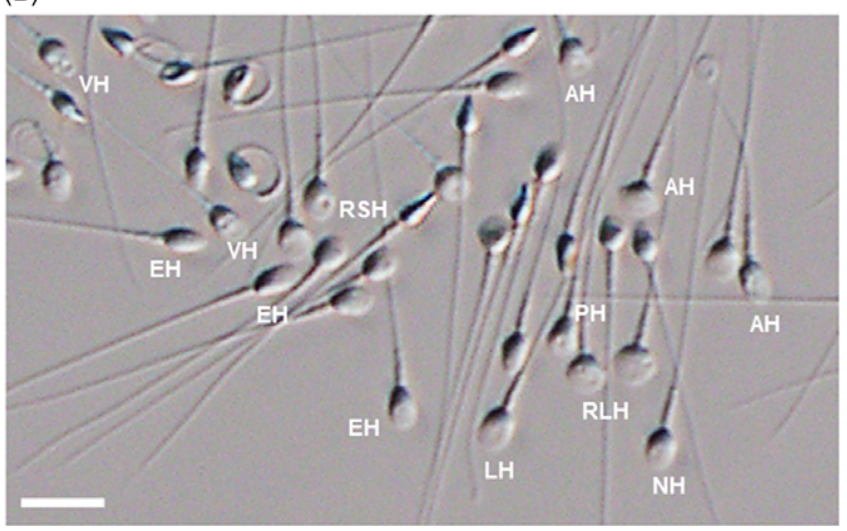

Figure 2. An experimental procedure for assessing the utility of sperm with different head shapes. (A) Enucleated mouse oocytes are injected with human sperm; sperm head size is measured after ICSI and analysed retrospectively. Images of each sperm head are used to calculate the aspect ratio. The magnified image of the inset square in 'Sperm selection and snapshot' illustrates how the aspect ratio is calculated from the length $(Y)$ and width $(X)$ of the sperm head. Scale bar represents $10 \mu \mathrm{m}$. (B) Spermatozoa viewed under an inverted microscope at $\times 400$ magnification. Spermatozoa with a range of sperm head shapes are present. $\mathrm{NH}$, morphologically normal head; LH, large head; RSH, round small head; RLH, round large head; AH, amorphous head; $\mathrm{EH}$, elongated head; $\mathrm{PH}$, pyriform head; $\mathrm{VH}$, vacuolated head. Scale bar represents $10 \mu \mathrm{m}$.

is very little evidence describing the relationship between sperm head shape and the presence of chromosome abnormalities (Lee et al., 1996). In this respect, it is desirable to perform chromosomal analyses at low magnification without using staining or similar approaches that disable ICSI post analysis.

Sperm morphology can also be analysed by motile sperm organelle morphology examination (MSOME) (Table 1). This high-magnification analysis (more than $\times 6000$ ) detects the presence or absence of vacuoles within the sperm head. Sperm with abnormal morphological characteristics, as determined by MSOME criteria, have an increased risk of DNA fragmentation (Bartoov et al., 2002). Subsequently, MSOME criteria have been used to select sperm for use in intracytoplasmic morphologically selected sperm injection (IMSI) (Table 1). Luna et al. (2015) reported that IMSI gave a significantly improved implantation rate and an improvement in embryo quality and development. Utsuno et al. (2013) described sperm head shape in detail using MSOME and reported that sperm with abnormal ellipticity and angularity had a higher rate of DNA fragmentation than sperm with a normal-shaped head (Utsuno et al., 2013). Various studies have compared the outcomes of ICSI based on conventional sperm parameters and IMSI (Bartoov et al., 2001, 2003; Berkovitz 
et al., 2005). Although these studies showed an association between sperm heads with or without vacuoles and the rates of implantation and pregnancy (Bartoov et al., 2003; Berkovitz et al., 2006; Hazout et al., 2006; Antinori et al., 2008), according to later studies, others have concluded that IMSI is only effective when there are indications of couples with multiple abnormal sperm parameters (Schachter-Safrai et al., 2019), including teratozoospermia (Perdrix and Rives, 2013), oligoasthenoteratozoospermia (Mangoli et al., 2019), or for recurrent implantation failure following ICSI (Boitrelle et al., 2014). Therefore, IMSI is currently only used in a limited number of clinical situations because of the limited effects.

From these studies, it is reasonable to conclude that the shape and size of the sperm head may affect fertilization rates and subsequent clinical outcomes with respect to the sperm used for ICSI treatments. To apply this knowledge in clinical practice, it is desirable to develop technologies and/or devices that can easily and objectively judge the shape and size, and acrosome status of the sperm head accurately, particularly using the $\times 400$ or $\times 600$ magnification images that are standard in many fertility clinics.

\section{Future perspectives for ARTs}

As described above, sperm selection for ICSI in human ART has generally been performed using subjective criteria. Recently, however, attempts have been made to apply an automated classification to sperm selection (Table 1). For example, a dictionary-learning technique (Shaker et al., 2017), a deep-learning-based method (McCallum et al., 2019; Riordon et al., 2019), and other automatic systems have been developed (Mirsky et al., 2017; Chang et al., 2017b). Moreover, using the publicly available Human Sperm Head Morphology dataset (HuSHeM), Shaker et al. (2017) compared adaptive patch-based dictionary learning (APDL) and cascade ensemble of support vector machines (CE-SVMs) for sperm selection. They reported that APDL has better accuracy and recall than CE-SVMs. Conversely, Riordon et al. (2019) showed that using the convolutional neural network model VGG16, they were able to obtain true positive rates comparable with those of the CE-SVM and APDL methods. The same group used a similar deep-learning technique to develop a method for recognizing sperm DNA fragmentation based on bright-field images, allowing selection for sperm with DNA integrity (McCallum et al., 2019). In addition, automatic classification using a gold standard for morphological sperm dataset (SCIANMorphoSpermGS; Chang et al., 2017a) and support vector machines (SVMs; Chang et al., 2017b), and a combination of interferometric phase microscopy and SVMs have been reported (Mirsky et al., 2017). Recently, Iqbal et al. (2020) established a morphological classification of human sperm heads (MC-HSH) that has higher accuracy than previously reported methods that use the SCIAN or HuSHeM datasets. Unfortunately, most of these analytical methods are based on images captured at ultrahigh magnification $(\times 6300-10,000)$ using fluorescence microscopy. In addition, these methods are technically difficult to perform in standard fertility clinics. Sperm selection for ICSI is performed using inverted microscopes at approximately $\times 400$ magnification in most ART clinics. While it is desirable to be able to select sperm at this magnification, it is extremely difficult to select sperm of ideal size and shape visually. Furthermore, it is not economically feasible to introduce IMSI systems into small clinics where staff may not be sufficiently experienced with ICSI, as only a small number of cases are processed routinely. By contrast, in large clinics dealing with a high number of ICSI cases, it may be difficult for embryologists and other staff to use IMSI in all cases as it is a time-consuming and laborious method. Considering these difficulties, a definition of strict criteria for sperm selection is essential. However, even if the injected sperm is of poor quality, oocytes can repair some of the damage in the sperm (Sakkas et al., 2015), suggesting that the ICSI operator may require less onerous methods for sperm selection along with other routine work. Recently, Javadi and Mirroshandel developed an automated assessment approach using a deep-learning-based method to detect morphological deformities in different parts of the human sperm head, acrosome, and vacuoles using nonstained and low-resolution images (Javadi and Mirroshandel, 2019). The same group also reported an automatic algorithm for detection of human sperm head malformations in real time, with low computation cost (Ghasemian et al., 2015) and for selection of the best sperm for ICSI (Mirroshandel et al., 2016). However, few studies have investigated the relationship between sperm images captured at low magnification for sperm selection for ICSI, and the relationship with embryo development, embryo quality, and clinical outcomes.

\section{Conclusion}

Retrospective analyses are required to investigate the relationship between individual sperm head size, shape, and acrosome status (assessed from bright-field images of a spermatozoon prior to injection into the oocyte) and the resulting embryonic, clinical, neonatal developmental potential, and birth defects. A collaborative analysis involving multiple ART clinics worldwide should allow us to create and define more stringent criteria for sperm selection with noninvasive, objective, real-time methods for ICSI (Figure 3). The information obtained from such studies will ultimately lead to the development of training data for artificial intelligence-based methods. It is important to note that we need to define the formats (file type, magnification, types of data collected) before initiating such international collaborative studies. Furthermore, as infertility is an increasing problem in many countries (Inhorn and Patrizio, 2015; Calhaz-Jorge et al., 2017; Irahara et al., 2017; De Geyter et al., 2018; Sunderam et al., 2020), it will become necessary to construct noninvasive, objective, real-time sperm selection systems for use when embryologists are performing ICSI. These systems should involve the use of an inverted microscope at $\times 400-600$ magnification for accurate sperm head measurements and evaluation. These images can then be applied for deep-learning selection methods. For the evaluation of the normality of genomic DNA integrity by dictionary-learning-based and/or deep-learning-based methods, observation at higher magnification $(\times 1000$ or higher $)$ would be necessary. We contend that if these procedures are introduced and established as standard in clinics, not only would there be fewer differences in sperm selection between ICSI operators, but fertilization rates, clinical outcomes, and even neonatal outcomes may also be improved. These approaches may take some time but will eventually improve and advance ARTs in the future.

Acknowledgement. We thank Daisuke Mashiko for insightful discussion.

Financial support. This work was supported in part by research grants from the Japan Society for the Promotion of Science KAKENHI grants (JP16H01319, JP16K07099 and JP19K06452 to J.U.); the Takeda Science Foundation (J.U.); the Kato Memorial Bioscience Foundation (J.U.); the Akiyama Life Science Foundation (J.U.); and the Joint Research Program of the Institute for Genetic Medicine, Hokkaido University (J.U.). 


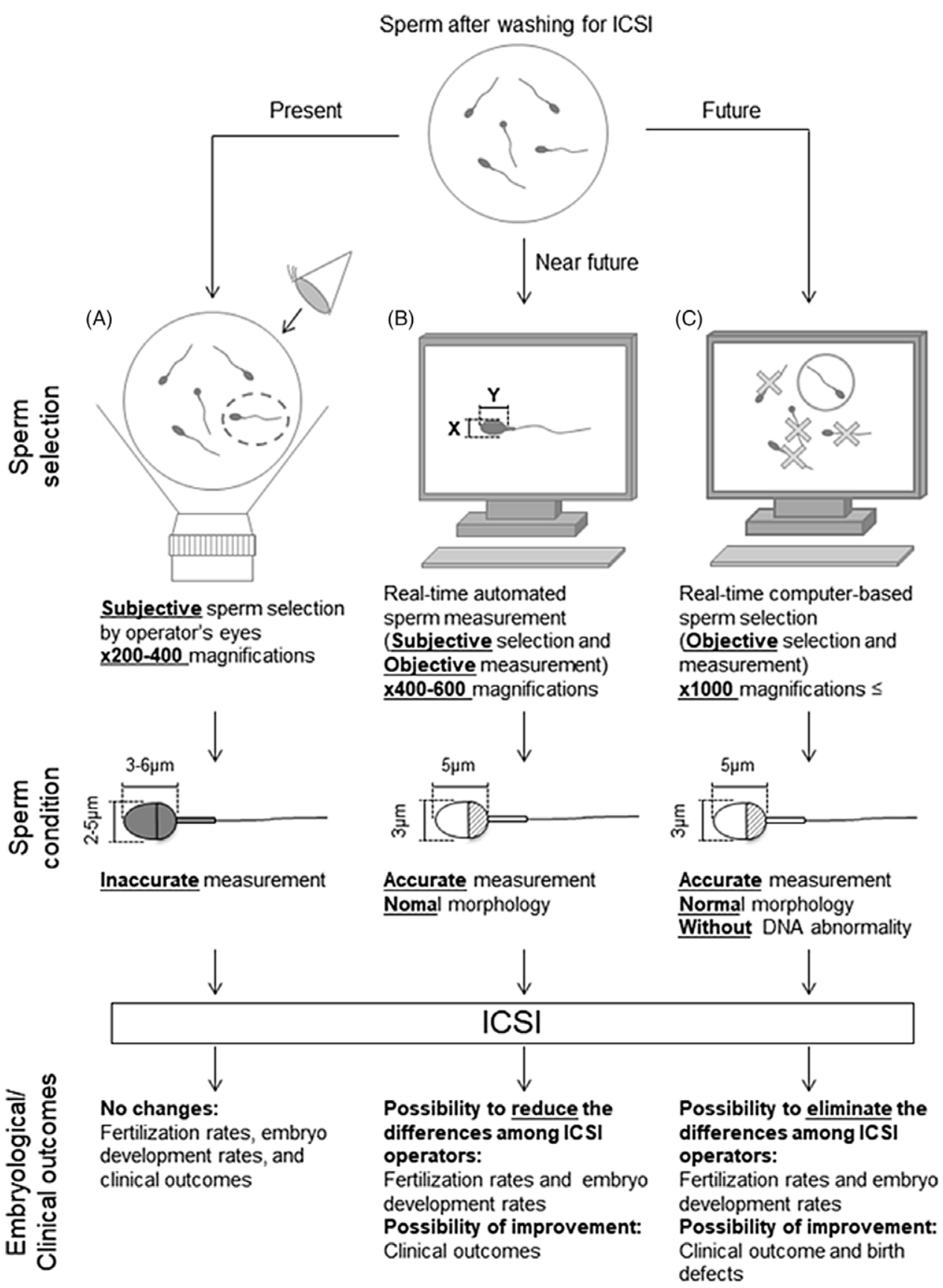

Figure 3. Schematic diagram of proposed sperm selection procedures at present and in the future. (A) Sperm selection methods for ICSI are currently subjective, performed by the operator's visual inspection. (B) Real-time automated sperm measurement after subjective selection by the operator in the near future. (C) As standardized knowledge increases in the future, real-time computer-based sperm selection may be possible.

Conflict of interest. Fumiaki Itoi, Toshinobu Miyamoto, Takehiro Himaki, Hiroyuki Honnma, Miho Sano and Jun Ueda declare that they have no conflict of interest.

Ethical standards. Not applicable.

\section{References}

Alshahrani S, Agarwal A, Assidi M, Abuzenadah AM, Durairajanayagam D, Ayaz A, Sharma R and Sabanegh E (2014). Infertile men older than 40 years are at higher risk of sperm DNA damage. Reprod Biol Endocrinol 12, 103.

Antinori M, Licata E, Dani G, Cerusico F, Versaci C, d'Angelo D and Antinori S (2008). Intracytoplasmic morphologically selected sperm injection: a prospective randomized trial. Reprod Biomed Online 16, 835-41.
Bartolacci A, Pagliardini L, Makieva S, Salonia A, Papaleo E and Vigano P (2018). Abnormal sperm concentration and motility as well as advanced paternal age compromise early embryonic development but not pregnancy outcomes: a retrospective study of 1266 ICSI cycles. J Assist Reprod Genet 35 , 1897-903.

Bartoov B, Berkovitz A and Eltes F (2001). Selection of spermatozoa with normal nuclei to improve the pregnancy rate with intracytoplasmic sperm injection. N Engl J Med 345, 1067-8.

Bartoov B, Berkovitz A, Eltes F, Kogosowski A, Menezo Y and Barak Y (2002). Real-time fine morphology of motile human sperm cells is associated with IVF-ICSI outcome. J Androl 23, 1-8.

Bartoov B, Berkovitz A, Eltes F, Kogosovsky A, Yagoda A, Lederman H, Artzi S, Gross M and Barak Y (2003). Pregnancy rates are higher with intracytoplasmic morphologically selected sperm 
injection than with conventional intracytoplasmic injection. Fertil Steril 80, 1413-9.

Bedford JM and Calvin HI (1974). The occurrence and possible functional significance of -S-S- crosslinks in sperm heads, with particular reference to eutherian mammals. J Exp Zool 188, 137-55.

Belloc S, Benkhalifa M, Junca AM, Dumont M, Bacrie PC and Menezo Y (2009). Paternal age and sperm DNA decay: discrepancy between chromomycin and aniline blue staining. Reprod Biomed Online 19, 264-9.

Berkovitz A, Eltes F, Yaari S, Katz N, Barr I, Fishman A and Bartoov B (2005). The morphological normalcy of the sperm nucleus and pregnancy rate of intracytoplasmic injection with morphologically selected sperm. Hum Reprod 20, 185-90.

Berkovitz A, Eltes F, Lederman H, Peer S, Ellenbogen A, Feldberg B and Bartoov B (2006). How to improve IVF-ICSI outcome by sperm selection. Reprod Biomed Online 12, 634-8.

Boitrelle F, Guthauser B, Alter L, Bailly M, Bergere M, Wainer R, Vialard F, Albert M and Selva J (2014). High-magnification selection of spermatozoa prior to oocyte injection: confirmed and potential indications. Reprod Biomed Online 28, 6-13.

Brahem S, Mehdi M, Elghezal H and Saad A (2011). Analysis of sperm aneuploidies and DNA fragmentation in patients with globozoospermia or with abnormal acrosomes. Urology 77, 1343-8.

Brykczynska U, Hisano M, Erkek S, Ramos L, Oakeley EJ, Roloff TC, Beisel C, Schubeler D, Stadler MB and Peters AH (2010). Repressive and active histone methylation mark distinct promoters in human and mouse spermatozoa. Nat Struct Mol Biol 17, 679-7.

Calhaz-Jorge C, De Geyter C, Kupka MS, de Mouzon J, Erb K, Mocanu E, Motrenko T, Scaravelli G, Wyns C and Goossens V (2017). Assisted reproductive technology in Europe, 2013: results generated from European registers by ESHRE. Hum Reprod 32, 1957-73.

Cassuto NG, Bouret D, Plouchart JM, Jellad S, Vanderzwalmen P, Balet R, Larue $\mathbf{L}$ and Barak Y (2009). A new real-time morphology classification for human spermatozoa: a link for fertilization and improved embryo quality. Fertil Steril 92, 1616-25.

Chang V, Garcia A, Hitschfeld N and Hartel S (2017a). Gold-standard for computer-assisted morphological sperm analysis. Comput Biol Med 83, 143-50.

Chang V, Heutte L, Petitjean C, Hartel S and Hitschfeld N (2017b). Automatic classification of human sperm head morphology. Comput Biol Med 84, 205-16.

Chapuis A, Gala A, Ferrieres-Hoa A, Mullet T, Bringer-Deutsch S, Vintejoux E, Torre A and Hamamah S (2017). Sperm quality and paternal age: effect on blastocyst formation and pregnancy rates. Basic Clin Androl 27, 2.

Clermont Y (1972). Kinetics of spermatogenesis in mammals: seminiferous epithelium cycle and spermatogonial renewal. Physiol Rev 52, 198-236.

De Geyter C, Calhaz-Jorge C, Kupka MS, Wyns C, Mocanu E, Motrenko T, Scaravelli G, Smeenk J, Vidakovic S, Goossens V; European IVF-monitoring Consortium (EIM) for the European Society of Human Reproduction and Embryology (ESHRE) (2018). ART in Europe, 2014: results generated from European registries by ESHRE: The European IVFmonitoring Consortium (EIM) for the European Society of Human Reproduction and Embryology (ESHRE). Hum Reprod 33, 1586-601.

De Vos A, Van De Velde H, Joris H, Verheyen G, Devroey $P$ and Van Steirteghem A (2003). Influence of individual sperm morphology on fertilization, embryo morphology, and pregnancy outcome of intracytoplasmic sperm injection. Fertil Steril 79, 42-8.

Frattarelli JL, Miller KA, Miller BT, Elkind-Hirsch K and Scott RT, Jr (2008). Male age negatively impacts embryo development and reproductive outcome in donor oocyte assisted reproductive technology cycles. Fertil Steril 90, 97-103.

Ghasemian F, Mirroshandel SA, Monji-Azad S, Azarnia M and Zahiri Z (2015). An efficient method for automatic morphological abnormality detection from human sperm images. Comput Methods Programs Biomed 122, 409-20.

Govin J, Caron C, Lestrat C, Rousseaux S and Khochbin S (2004). The role of histones in chromatin remodelling during mammalian spermiogenesis. Eur J Biochem 271, 3459-69.
Griswold MD (2016). Spermatogenesis: the commitment to meiosis. Physiol Rev 96, 1-17.

Hammoud SS, Nix DA, Zhang H, Purwar J, Carrell DT and Cairns BR (2009). Distinctive chromatin in human sperm packages genes for embryo development. Nature 460, 473-8.

Hazout A, Dumont-Hassan M, Junca AM, Cohen Bacrie P and Tesarik J (2006). High-magnification ICSI overcomes paternal effect resistant to conventional ICSI. Reprod Biomed Online 12, 19-25.

Inhorn MC and Patrizio P (2015). Infertility around the globe: new thinking on gender, reproductive technologies and global movements in the 21 st century. Hum Reprod Update 21, 411-26.

Iqbal I, Mustafa G and Ma J (2020). Deep Learning-Based Morphological Classification of Human Sperm Heads. Diagnostics (Basel) 10, 325.

Irahara M, Kuwahara A, Iwasa T, Ishikawa T, Ishihara O, Kugu K, Sawa R, Banno K and Saito H (2017). Assisted reproductive technology in Japan: a summary report of 1992-2014 by the Ethics Committee, Japan Society of Obstetrics and Gynecology. Reprod Med Biol 16, 126-32.

Irvine DS (1998). Epidemiology and aetiology of male infertility. Hum Reprod 13 (Suppl 1), 33-44.

Javadi S and Mirroshandel SA (2019). A novel deep learning method for automatic assessment of human sperm images. Comput Biol Med 109, 182-94.

Jung YH, Sauria MEG, Lyu X, Cheema MS, Ausio J, Taylor J and Corces VG (2017). Chromatin states in mouse sperm correlate with embryonic and adult regulatory landscapes. Cell Rep 18, 1366-82.

Kaarouch I, Bouamoud N, Madkour A, Louanjli N, Saadani B, Assou S, Aboulmaouahib S, Amzazi S, Copin H, Benkhalifa $M$ and Sefrioui $O$ (2018). Paternal age: negative impact on sperm genome decays and IVF outcomes after 40 years. Mol Reprod Dev 85, 271-80.

Kissin DM, Zhang Y, Boulet SL, Fountain C, Bearman P, Schieve L, Yeargin-Allsopp $\mathbf{M}$ and Jamieson DJ (2015). Association of assisted reproductive technology (ART) treatment and parental infertility diagnosis with autism in ART-conceived children. Hum Reprod 30, 454-65.

Kruger TF, Acosta AA, Simmons KF, Swanson RJ, Matta JF and Oehninger S (1988). Predictive value of abnormal sperm morphology in in vitro fertilization. Fertil Steril 49, 112-7.

Lee JD, Kamiguchi Y and Yanagimachi R (1996). Analysis of chromosome constitution of human spermatozoa with normal and aberrant head morphologies after injection into mouse oocytes. Hum Reprod 11, 1942-6.

Luna D, Hilario R, Duenas-Chacon J, Romero R, Zavala P, Villegas L and Garcia-Ferreyra J (2015). The IMSI procedure improves laboratory and clinical outcomes without compromising the aneuploidy rate when compared to the classical ICSI procedure. Clin Med Insights Reprod Health 9, 29-37.

Luna M, Finkler E, Barritt J, Bar-Chama N, Sandler B, Copperman AB and Grunfeld L (2009). Paternal age and assisted reproductive technology outcome in ovum recipients. Fertil Steril 92, 1772-5.

Mangoli E, Khalili MA, Talebi AR, Agha-Rahimi A, Soleimani M, Faramarzi A and Pourentezari M (2019). IMSI procedure improves clinical outcomes and embryo morphokinetics in patients with different aetiologies of male infertility. Andrologia 51, e13340.

Mansour RT, Aboulghar MA, Serour GI, Amin YM and Ramzi AM (1995). The effect of sperm parameters on the outcome of intracytoplasmic sperm injection. Fertil Steril 64, 982-6.

Mashiko D, Ikawa M and Fujimoto K (2017). Mouse spermatozoa with higher fertilization rates have thinner nuclei. PeerJ 5, e3913.

McCallum C, Riordon J, Wang Y, Kong T, You JB, Sanner S, Lagunov A, Hannam TG, Jarvi K and Sinton D (2019). Deep learning-based selection of human sperm with high DNA integrity. Commun Biol 2, 250.

Mirroshandel SA, Ghasemian F and Monji-Azad S (2016). Applying data mining techniques for increasing implantation rate by selecting best sperms for intra-cytoplasmic sperm injection treatment. Comput Methods Programs Biomed 137, 215-29.

Mirsky SK, Barnea I, Levi M, Greenspan H and Shaked NT (2017). Automated analysis of individual sperm cells using stain-free interferometric phase microscopy and machine learning. Cytometry A 91, 893-900.

Nagy ZP, Liu J, Joris H, Verheyen G, Tournaye H, Camus M, Derde MC, Devroey P and Van Steirteghem AC (1995). The result of intracytoplasmic 
sperm injection is not related to any of the three basic sperm parameters. Hum Reprod 10, 1123-9.

Nishikawa K, Itoi F, Nagahara M, Jose M, Matsunaga A, Ueda J and Iwamoto T (2018). The normality of sperm in an infertile man with ring chromosome 15: a case report. J Assist Reprod Genet 35, 251-6.

Palermo G, Joris H, Devroey P and Van Steirteghem AC (1992). Pregnancies after intracytoplasmic injection of single spermatozoon into an oocyte. Lancet 340, 17-8.

Perdrix A and Rives N (2013). Motile sperm organelle morphology examination (MSOME) and sperm head vacuoles: state of the art in 2013. Hum Reprod Update 19, 527-41.

Potter SS (2018). Single-cell RNA sequencing for the study of development, physiology and disease. Nat Rev Nephrol 14, 479-92.

Riordon J, McCallum C and Sinton D (2019). Deep learning for the classification of human sperm. Comput Biol Med 111, 103342.

Rumbold AR, Sevoyan A, Oswald TK, Fernandez RC, Davies MJ and Moore VM (2019). Impact of male factor infertility on offspring health and development. Fertil Steril 111, 1047-53.

Sagi-Dain L, Sagi S and Dirnfeld M (2015). Effect of paternal age on reproductive outcomes in oocyte donation model: a systematic review. Fertil Steril 104, 857-65 e851.

Sakkas D, Ramalingam M, Garrido N and Barratt CL (2015). Sperm selection in natural conception: what can we learn from Mother Nature to improve assisted reproduction outcomes? Hum Reprod Update 21, 711-26.

Sandin S, Nygren KG, Iliadou A, Hultman CM and Reichenberg A (2013). Autism and mental retardation among offspring born after in vitro fertilization. JAMA 310, 75-84.

Schachter-Safrai N, Karavani G, Reuveni-Salzman A, Gil M and Ben-Meir A (2019). Which semen analysis correlates with favorable Intracytoplasmic morphologically selected sperm injection (IMSI) outcomes? Eur J Obstet Gynecol Reprod Biol 234, 85-8.

Shaker F, Monadjemi SA, Alirezaie J and Naghsh-Nilchi AR (2017). A dictionary learning approach for human sperm heads classification. Comput Biol Med 91, 181-90.

Shapiro E, Biezuner T and Linnarsson S (2013). Single-cell sequencing-based technologies will revolutionize whole-organism science. Nat Rev Genet 14, 618-30.

Sharma R, Agarwal A, Rohra VK, Assidi M, Abu-Elmagd M and Turki RF (2015). Effects of increased paternal age on sperm quality, reproductive outcome and associated epigenetic risks to offspring. Reprod Biol Endocrinol 13, 35.

Steptoe PC and Edwards RG (1978). Birth after the reimplantation of a human embryo. Lancet 2, 366

Sunderam SK, Kissin DM, Zhang Y, Jewett A, Boulet SL, Warner L, Kroelinger CD and Barfield WD (2020). Assisted Reproductive Technology Surveillance - United States, 2017. MMWR Surveill Summ 69, $1-20$.

Svalander P, Jakobsson AH, Forsberg AS, Bengtsson AC and Wikland M (1996). The outcome of intracytoplasmic sperm injection is unrelated to 'strict criteria' sperm morphology. Hum Reprod 11, 1019-22.

Ueda J, Harada A, Urahama T, Machida S, Maehara K, Hada M, Makino Y, Nogami J, Horikoshi N, Osakabe A, Taguchi H, Tanaka H, Tachiwana $H$, Yao T, Yamada M, Iwamoto T, Isotani A, Ikawa M, Tachibana T, Okada Y, Kimura H, Ohkawa Y, Kurumizaka $H$ and Yamagata K (2017). Testis-specific histone variant H3t gene is essential for entry into spermatogenesis. Cell Rep 18, 593-600.

Utsuno H, Oka K, Yamamoto A and Shiozawa T (2013). Evaluation of sperm head shape at high magnification revealed correlation of sperm DNA fragmentation with aberrant head ellipticity and angularity. Fertil Steril 99, 1573-80.

World Health Organization (2010). WHO Laboratory Manual for the Examination and Processing of Human Semen. World Health Organization, Geneva.

Wu Y, Kang X, Zheng H, Liu H, Huang Q and Liu J (2016). Effect of paternal age on reproductive outcomes of intracytoplasmic sperm injection. PLoS One 11, e0149867.

Yamaguchi K, Hada M, Fukuda Y, Inoue E, Makino Y, Katou Y, Shirahige K and Okada Y (2018). Re-evaluating the localization of sperm-retained histones revealed the modification-dependent accumulation in specific genome regions. Cell Rep 23, 3920-32.

Zahiri Z and Ghasemian F (2019). Is it necessary to focus on morphologically normal acrosome of sperm during intracytoplasmic sperm injection? Indian J Med Res 150, 477-85.

Zhao M, Shirley CR, Hayashi S, Marcon L, Mohapatra B, Suganuma R, Behringer RR, Boissonneault G, Yanagimachi R and Meistrich ML (2004). Transition nuclear proteins are required for normal chromatin condensation and functional sperm development. Genesis 38, 200-13. 